\section{Rapid Estimation of Cabbage Head Volume across a Population Varying in Head Shape: A Test of Two Geometric Formulae}

\author{
Theodore J.K. Radovich ${ }^{1}$ and \\ Matthew D. Kleinhenz ${ }^{2}$
}

AdDitional INDEX words. density, maturity, quality, yield

SUMMARY. Volume measurements are useful in crop quality management because they offer three-dimensional estimates of commodity size, which is often closely related to commodity weight and density. The objective of this study was to compare volume estimates calculated with the sphere and spherical ellipsoid volume formulae with direct measures of volume via water displacement across a population of cabbage (Brassica olevacea Capitata Group) heads varying widely in shape. A total of 157 heads with polar $(P)$ : equatorial $(E)$ diameter ratios ranging between 0.5 (flat) to 2.1 (tall) were harvested at horticultural maturity from plants grown in 2002 and 2003 at the Ohio Agricultural Research and Development Center (OARDC) in Wooster, Ohio. The sphere formula underestimated volume in heads with $\mathrm{P}: \mathrm{E}$ ratios $<1$ and overestimated volume in heads with $\mathrm{P}: \mathrm{E}$ ratios $>1$. Use of the spherical ellipsoid formula reduced the shapedependency of volume estimates and

Department of Horticulture and Crop Science, The Ohio State University, Ohio Agricultural Research and Development Center (OARDC), 1680 Madison Avenue, Wooster, Ohio 44691-4096.

Salaries and research support provided in part by State and Federal funds appropriated to the Ohio Agricultura Research and Development Center, The Ohio State University. Work also supported in part by grants from the Ohio Vegetable and Small Fruit Research and Development Program. Use of trade names does not imply endorsement of the products named nor criticism of similar ones not named. Journal article number HCSO3-42.

The important contributions of Nate Honeck, Sonia Walker, John Elliott, Stacy Reid, Ken Chamberlain, and the OARDC Office of Communications and Technology are gratefully acknowledged.

${ }^{1}$ Graduate research associate.

${ }^{2}$ Assistant professor; to whom reprint requests should be addressed. was determined to be a valuable tool for the accurate, precise, and rapid measurement of head volume.

$\mathrm{V}$ egetable crop quality depends on many traits, including chemical composition, color, size, shape, weight, and density (Rubatzky and Yamaguchi, 1997). Measures of commodity volume are particularly valuable because they provide threedimensional estimates of commodity size and allow for calculations of density (Beyer, 1985). Volume is also an important component of yield in horticultural crops (Kalloo and Bergh, 1993). Direct measures of volume via water displacement are time consuming and commercially impractical; therefore, formulae to calculate volume in a range of crops from measures in two dimensions are preferred (Currence et al., 1944; Jenni et al., 1996; Marcelis, 1992; Mutschler et al., 1986; Ngouajio et al., 2003). Generally, these formulae correct for irregularities in commodity shape. For example, a modified formula for spheroid volume may be used to estimate the volume of mature muskmelon (Cucumis melo) fruit (Currence et al., 1944). The formula includes a correction factor for shape (i.e., fruit length : width ratio) based on dozens of measurements on each of 80 individual muskmelon fruit. This formula has been employed to estimate the volume of immature muskmelon ovaries and bell pepper (Capiscum annuum) fruit, with varying success (Jenni et al., 1996; Ngouajio et al., 2003). Volume formulae not including a correction factor may also be used to estimate commodity volume. For example, predicted and actual (water displacement) volumes of cucumber (Cucumis sativus) fruit may be well correlated when fruit volume is estimated from fruit length and average circumference values using the formula for the volume of a cylinder (Marcelis, 1992). In tomato (Lycopersicon esculentum), a strong relationship has been observed between actual fruit volume and volume predicted from fruit height and width using the formula for the volume of a spherical ellipsoid (Mutschler et al., 1986). In cucumber and tomato, geometrically derived volumes may also correlate well to individual fruit weight (Marcelis, 1992; Mutschler et al., 1986). Similar formulae may also be applied to cabbage. For example, 
most commercially important cabbage cultivars produce spherical, or nearly spherical heads, and the formula for sphere volume can be employed to estimate head volume and predict crop yield from mean head diameters (Kleinhenz, 2003; Wszelaki and Kleinhenz, 2003). Volume is also used to calculate density, an important indicator of cabbage head maturity (Isenberg et al., 1975; Radovich et al., 2004a). However, direct comparisons of head volume estimates from the sphere formula and water displacement have not been reported. Also, although spherical heads are preferred in most markets, much genetic diversity exists for head shape, and unusually shaped cabbage heads have potential niche market value (Kleinhenz and Wszelaki, 2003; Swaider and Ware, 2002). Environmental and developmental factors are also important, with the head shape of specific cultivars depending on planting date, plant population, soil moisture, and developmental stage (Kleinhenz and Wszelaki, 2003; Radovich et al., 2004a, 2004b; Stofella and Fleming, 1990; Sundstrom and Story, 1984). Since the estimation of cabbage yield and maturity depends on head volume, a rapid and reliable method of volume measurement is integral to the management of cabbage quality. Therefore, the objective of this study was to compare estimates of head volume using the sphere and spherical ellipsoid formulae with measures taken using water displacement. Heads of four test groups comprising a large population containing a wide range in head shape were used for this purpose.

\section{Materials and methods}

Plant materials. A total of 157 mature cabbage heads were harvested from four test groups grown at the Ohio Agricultural Research and Development Center in Wooster (lat. $40^{\circ} 47^{\prime} \mathrm{N}$, long. $81^{\circ} 55^{\prime} \mathrm{W}$ ) in 2002 and 2003 . For all test groups, soil type was a Wooster silt loam (fine-loamy, Mixed, Mesic Typic Fragiudalf), with $4.3 \%$ organic matter and $\mathrm{pH}=6.6$. Heads were selected to ensure a broad range in head shape within the population tested (Fig. 1). The cultivars and management practices used to produce the source population varied and are described below.

In 2002, 6-week-old seedlings of 'Bravo' (BRV02) were planted to the field 10 June using a single-row mechanical transplanter. Plant spacing was $0.3 \mathrm{~m}(1 \mathrm{ft})$ within single $18.3-\mathrm{m}-(60 \mathrm{ft})$ long rows with 1.2 $\mathrm{m}(4 \mathrm{ft})$ between treatment rows. Fertilizer was applied to the field prior to transplanting at the rate of 560.4 $\mathrm{kg} \cdot \mathrm{ha}^{-1}(500 \mathrm{lb} / \mathrm{acre})$ of 10-20-20 fertilizer $(10 \mathrm{~N}-8.7 \mathrm{P}-16.6 \mathrm{~K})$. Irrigation was applied as previously reported (Radovich et al., 2004a) so that plants experienced moisture stress either during frame development (FS), during head development (HS), throughout development (FHS), or not at all (NS). Standard pest management strategies, based on scouting, thresholds, and application of labeled pesticides, were employed (Kleinhenz and Wszelaki, 2003 ). At $86 \mathrm{~d}$ after planting (DAP), three heads from each of four replicates were harvested from each treatment, for a total of 48 heads. Heads were stored at $7.2^{\circ} \mathrm{C}\left(45^{\circ} \mathrm{F}\right)$ for $7 \mathrm{~d}$ prior to volume estimation.

In 2003, 6-week-old seedlings of 'Early Jersey Wakefield' (EJW) and 'Early Flat Dutch' (EFD) were planted to the field 17 June. Fertilizer was applied 1 month prior to planting at the rate of $448.3 \mathrm{~kg} \cdot \mathrm{ha}^{-1}$ (400 lb/acre) of 19-19-19 fertilizer (19N-8.3P-15.8K). Row length, plant spacing, and pest management practices were as in BRV02. Irrigation was applied during times of rainfall deficit to mitigate stress throughout plant development. Sixty-one (EJW) or 29 (EFD) heads with a shape characteristic for each cultivar (i.e., tall or flat) were harvested at horticultural maturity, which corresponded to 65 and 86 DAP for EJW and EFD, respectively. Heads were stored at $7.2^{\circ} \mathrm{C}$ for up to $21 \mathrm{~d}$ prior to volume estimation.

In 2003, 6-week-old seedlings of

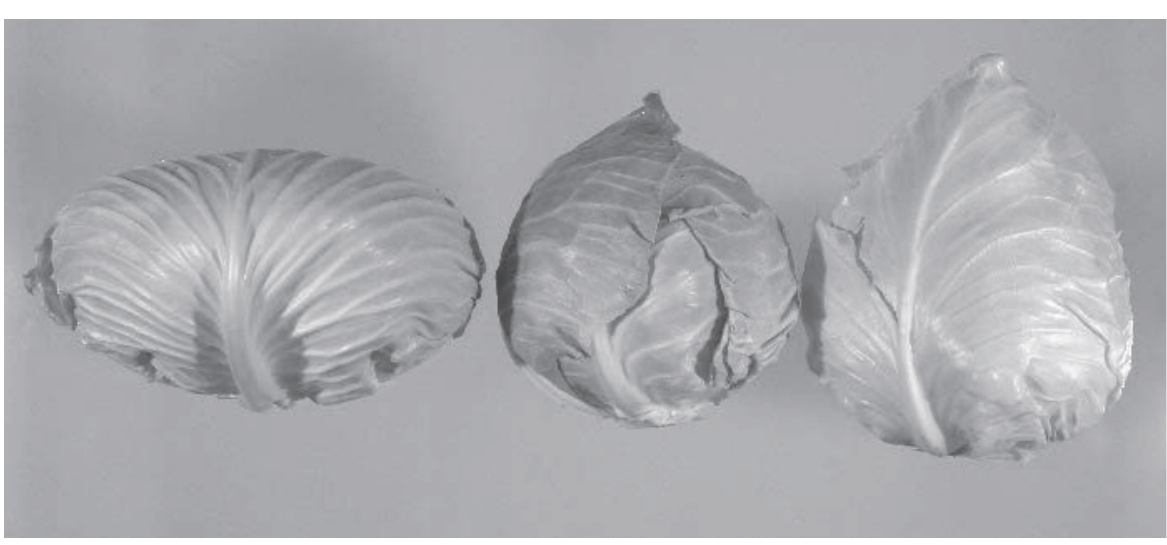

Fig. 1. Representative heads of 'Early Flat Dutch' (left), 'Bravo' (center), and 'Early Jersey Wakefield' (right).

'Bravo' (BRV03) were grown as EJW and EFD with the exception of irrigation, which was applied as in BRV02. Nineteen heads were harvested at 86 DAP. Heads were stored at 7.2 ${ }^{\circ} \mathrm{C}$ for up to $2 \mathrm{l} \mathrm{d}$ prior to volume estimation.

Volume estimation. Heads were prepared for measurement by removing all wrapper leaves not tightly associated with the head $(\sim 3-4)$ and weighed using a commercial field scale $(\mathrm{A}$ and $\mathrm{D}$ Weighing, Milpitas, Calif.). Mean head diameter (MD) was calculated from measures of head polar and equatorial diameters (PD and ED, respectively) taken with a $50-\mathrm{cm}$ (19.7 inches) sapling caliper (Haglof Inc., Madison, Miss.). The volume of each head was then estimated using both the sphere and spherical ellipsoid formulae

$$
\begin{aligned}
& \text { 4/3.pi } \cdot(1 / 2 \mathrm{MD})^{3} \text { and } \\
& 4 / 3 \cdot p i \cdot(1 / 2 \mathrm{PD}) \cdot(1 / 2 \mathrm{ED})^{2} \text {, }
\end{aligned}
$$

respectively (Beyer, 1985). The sphere and spherical ellipsoid formulae may be simplified to $\mathrm{MD}^{3} / 6$ and $\left(\mathrm{PD} \cdot \mathrm{ED}^{2}\right) / 6$, respectively (Ngouajio et al., 2003). The spherical ellipsoid formula has both a prolate form giving greater weight to the major axis $\left[\left(\mathrm{PD}^{2} \cdot \mathrm{ED}\right) / 6\right]$, and an oblate form in which the minor axis is emphasized [(PD.ED $\left.\left.{ }^{2}\right) / 6\right]$ (Beyer, 1985). Variation in ED is thought to contribute more than variation in PD to variability in head volume (Radovich et al., 2004b), and ED explained more variation $\left(r^{2}=0.82\right)$ in head displacement volume than PD $\left(r^{2}=0.62\right)$ in these data. Therefore, the oblate form was used here. Displacement volume of each head was recorded concurrently using the procedure reported by Isenberg et al. (1975), with some
Hroilkilunothy · July-September 2004 14(3) 
modifications. An 18.9-L (5 gal) plastic bucket was modified by drilling a 3 -cm-diameter ( 1.2 inch) hole $\sim 5 \mathrm{~cm}$ (2.0 inch) from the rim, and fitting a polyvinyl chloride (PVC) elbow joint through the hole to form a downwardfacing spout to allow the collection of water displaced into a 6-L (1.6 gal) plastic tub. To initiate measures of head volume, water was added to the bucket until it began to run from the spout, with excess water allowed to drain from the bucket to the tub, from which it was emptied. Thereafter, a sharpened metal $\operatorname{rod}[18 \times 0.5 \mathrm{~cm}(7.1 \times 0.20$ inches)] was inserted $\sim 5 \mathrm{~cm}$ into the core and the head was placed into a thin plastic produce bag (Crown Poly, Los Angeles) to prevent the intrusion of water into the submersed head. One end of a $1-\mathrm{m}(3.3 \mathrm{ft})$ length of $8 \times 0.6-\mathrm{mm}(0.3 \times 0.02 \mathrm{inch})$ rubber tubing (Saint-Gobain Performance Plastics, Akron, Ohio) was attached to the metal rod and placed in contact with the head inside the bag. A vacuum generated with an aspirator at the other end of the tubing secured the bag tightly around the head. The head was then slowly submersed until displaced water stopped running from the spout. Displaced water volume was determined with a $1-\mathrm{L}(0.3 \mathrm{gal})$ graduated cylinder, scored in 10 - $\mathrm{mL}(0.34$ $\mathrm{fl} \mathrm{oz}$ ) increments. Analysis of variance and means separation were conducted with SAS for Windows v.8 (Statistical Analysis System, Cary, N.C.) and with the Regression Wizard of SigmaPlot 2000 for Windows v. 6.0 (SPSS Inc., Chicago).

\section{Results and discussion}

Mean polar:equatorial (P:E) diameter values varied widely among heads from the different test groups (Table 1). The relatively wide range observed within and across BRV02 and BRV03 was attributed to environmental factors, such as irrigation regime and annual variation in precipitation, air temperature, and relative humidity (Radovich et al. 2004b, data not shown). However, this variation represents the range of values commonly found among commercial cabbage cultivars (Kleinhenz and Wszelaki, 2003; Sundstrom and Story, 1984). In contrast, head shapes observed in EFD and EJW were outside the range of current commercial types and represent the extreme range of head
Table 1. Differences among test groups of 'Early Jersey Wakefield' (EJW), 'Bravo' 2002 (BRV02), 'Bravo' 2003 (BRV03), and 'Early Flat Dutch' (EFD) in head shape, and relationships between predicted and actual (displacement) head volume values.

\begin{tabular}{|c|c|c|c|c|c|c|}
\hline \multirow{3}{*}{$\begin{array}{l}\text { Test } \\
\text { group }\end{array}$} & \multirow{2}{*}{\multicolumn{2}{|c|}{$\begin{array}{c}\text { Polar: } \\
\text { equatorial diam }\end{array}$}} & \multicolumn{2}{|c|}{$\begin{array}{l}\text { Coefficient of } \\
\text { determination }^{\mathrm{z}}\end{array}$} & \multicolumn{2}{|c|}{$\begin{array}{l}\text { Predicted: } \\
\text { actual volume }\end{array}$} \\
\hline & & & \multirow[b]{2}{*}{ Sphere } & \multirow{2}{*}{$\begin{array}{l}\text { Spherical } \\
\text { ellipsoid }\end{array}$} & \multirow[b]{2}{*}{ Sphere } & \multirow{2}{*}{$\begin{array}{l}\text { Spherical } \\
\text { ellipsoid }\end{array}$} \\
\hline & Mean & SD & & & & \\
\hline EJW & 1.46 & 0.13 & 0.73 & 0.80 & $1.41 \mathrm{a}^{\mathrm{y}}$ & $1.10 \mathrm{~b}$ \\
\hline BRV02 & 1.15 & 0.22 & 0.99 & 0.95 & $1.06 \mathrm{bc}$ & $0.98 \mathrm{~cd}$ \\
\hline BRV03 & 0.86 & 0.05 & 0.90 & 0.91 & $1.00 \mathrm{bcd}$ & $1.07 \mathrm{bc}$ \\
\hline EFD & 0.65 & 0.04 & 0.84 & 0.84 & $0.91 \mathrm{~d}$ & $1.05 \mathrm{bc}$ \\
\hline
\end{tabular}

${ }^{2} \mathrm{r}^{2}$ values of relationships between predicted volume using either the sphere or spherical ellipsoid formula and volume measured by displacement. $\mathrm{N}=6 \mathrm{l}$ (EJW), 48 (BRV02), 19 (BRV03) or 29 (EFD).

yredicted : actual volume values followed by the same letter are not significantly different from each other according to Duncan's multiple range test $(P \leq 0.05)$.

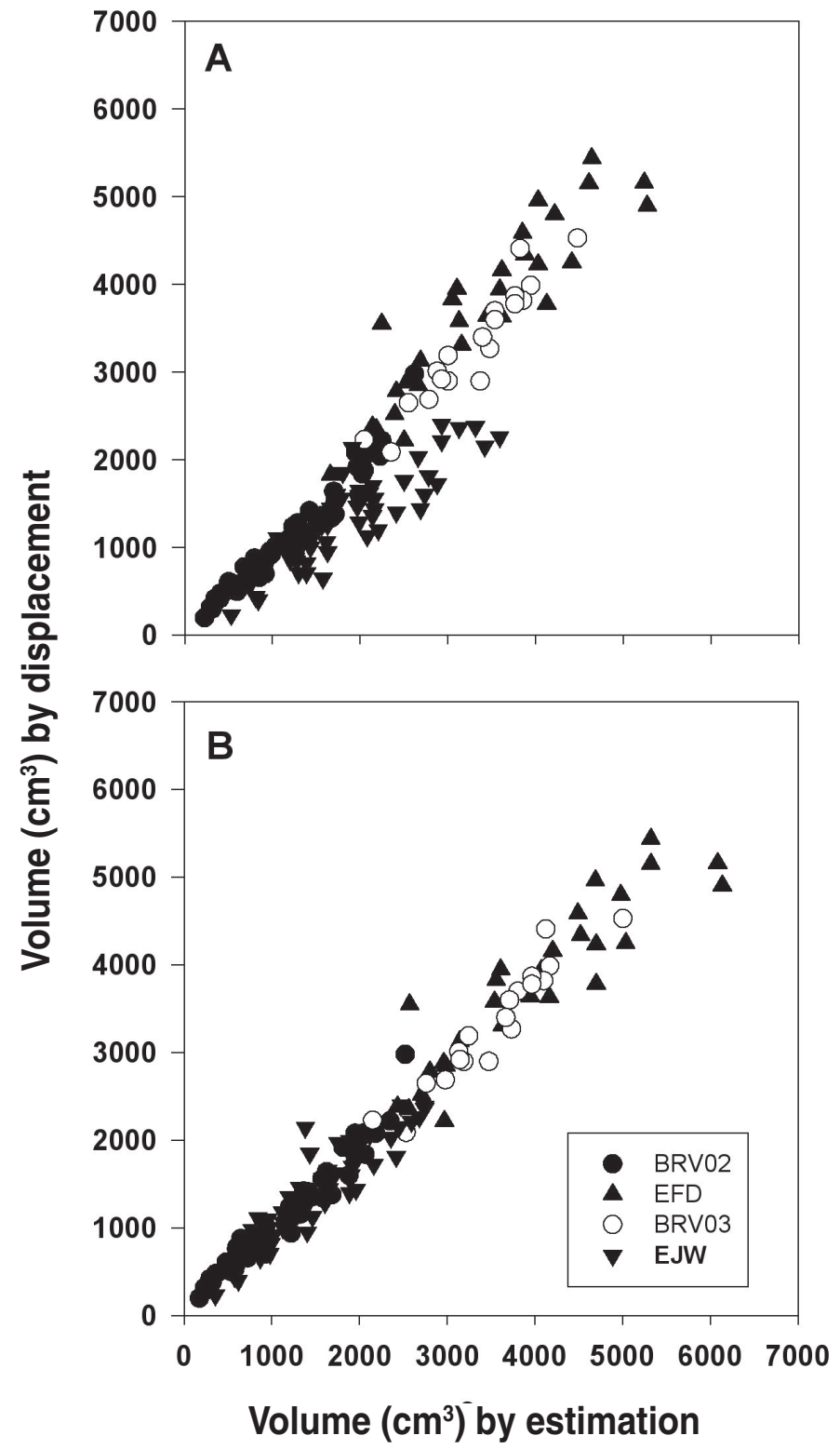

Fig. 2. The relationship between cabbage head volume estimated using the formula for a sphere (A) or spherical ellipsoid (B) and measured by displacement. Across test groups $(\mathrm{N}=157), r^{2}=0.88(\mathrm{~A})$ and $0.96(\mathrm{~B}) .1 \mathrm{~cm}^{3}=0.06 \mathrm{inch}^{3}$. 
shape in conventional markets. Therefore, heads from the four test groups collectively comprised a population spanning a large range in head shape (Swaider and Ware, 2002). Across the population, values for volume by displacement were more strongly correlated with estimates of volume based on the spherical ellipsoid rather than the sphere formula. A closer fit of displacement-spherical ellipsoid formula data for EJW, in particular, may have been responsible for this overall effect (Table 1, Fig. 2).

Plotting the ratio of volume predicted by the sphere formula to displacement volume against head $\mathrm{P}: \mathrm{E}$ values revealed that the sphere formula under- and over-estimated volume in heads with $\mathrm{P}$ : E ratios $<\mathrm{l}$ and $>1$, respectively (Table 1 ). Moreover, predicted:actual volume values for EFD and EJW were closer to 1 (i.e., most accurate) when the spherical ellipsoid formula was used (Table 1 ). It is also important to note that there was little difference in $r^{2}$ and no significant difference in accuracy between the two estimates for BRV02 or BRV03, suggesting that either formula may be used for heads with average P:E ratios of $0.8-1.2$, which are common in commercial settings. However, the spherical ellipsoid formula may allow for the most accurate and precise estimates of cabbage head volume and, therefore, density across a wider range in head shape. As in previous studies, a proportional relationship between individual head volume and weight was also observed in this study, $\left(r^{2}=0.92\right.$; $P \leq 0.001)$. In experimental and commercial fields, the average head volume of a sampled area has been successfully employed to predict the yield of that area (Kleinhenz, 2003). The potential application of head volume to predict crop yield reinforces the importance of accurate and precise measures of volume. With this in mind, we suspect that the measurement of diameter along a third axis and calculation of volume using the formula for a triaxial ellipsoid (Beyer, 1985) would further improve the accuracy of volume estimates of EJW and similarly shaped (i.e., tall-headed) cultivars. However, it is unclear whether improvements in the accuracy of volume estimates in these cases would offset the additional time required to measure diameter along a third axis.

Finally, formulae-based estimates of volume required less than $1 \mathrm{~min}$, compared to measures of volume by displacement, which required $\sim 5 \mathrm{~min}$. Therefore, we conclude that formulae-based estimates of cabbage head volume, especially those employing the spherical ellipsoid formula, are applicable in commercial and research settings when rapid, accurate, and precise measurements of head size, weight, density, and maturity are needed.

\section{Literature cited}

Beyer, W.H. 1985. CRC Handbook of mathematical sciences. 5th ed. CRC Press, Boca Raton, Fla.

Currence, T.M., R.E. Lawson, and R.M. Brown. 1944. A rapid method for finding the volume and density of muskmelon fruits. J. Agr. Res. 68: 427-440.

Isenberg, F.M.R., A. Pendergrass, J.E. Carroll, L. Howell, and E.B. Oyer. 1975. The use of weight, density, heat units and solar radiation to predict the maturity of cabbage for storage. J. Amer. Soc. Hort. Sci. 100:313-316.

Jenni, S., K.A. Stewart, G. Bourgeois, and Daniel C. Cloutier. 1996. Nondestructive volume estimation for growth analysis of eastern-type muskmelon ovaries. HortScience 31:1236.

Kalloo, G. and B.O. Bergh. 1993. Genetic improvement of vegetable crops. Pergamon Press, Oxford, U.K.

Kleinhenz, M.D. 2003. A proposed tool for preharvest estimation of cabbage yield. HortTechnology 13:182-185.
Kleinhenz, M.D. and A. Wszelaki. 2003. Yield and relationships among head traits in cabbage (Brassica oleracea, L. Capitata Group) as influenced by planting date and cultivar. I. Fresh market. HortScience 38:1349-1354

Marcelis, L.F.M. 1992. Non-destructive measurements and growth analysis of the cucumber fruit. J. Hort. Sci. 67:457-464.

Mutschler, M.A., L. Yasamura, and J. Sethna. 1986. Estimation of tomato fruit volume from fruit measurements. Rpt. Tomato Genet. Coop. 36:10.

Ngouajio, M., W. Kirk, and R. Goldy. 2003. A simple model for rapid and nondestructive estimation of bell pepper fruit volume. HortScience 38:509-511.

Radovich, T.J.K., M.D. Kleinhenz, J.F. Delwiche, and R.E. Liggett. 2004a. Triangle tests indicate that irrigation timing affects fresh cabbage sensory quality. Food Quality and Preference 15:471-476.

Radovich, T.J.K., M.D. Kleinhenz, and N.J. Honeck. 2004b. Important cabbage head traits and their relationships at five points in development. J. Veg. Crop Production. (In press.)

Rubatzky, V.E. and M. Yamaguchi. 1997. World vegetables. Chapman and Hall, New York.

Stofella, P.J. and M.F. Fleming. 1990. Plant population influences yield variability of cabbage. J. Amer. Soc. Hort. Sci. 115:708-711.

Sundstrom, F.J. and R.N. Story. 1984. Cultivar and growing season effects on cabbage head development and weight loss during storage. HortScience 19:589-590.

Swaider, J.M. and G.W. Ware. 2002. Cole Crops, p. 267-292. In: G.W. Ware and J. P. McCollum (eds.). Producing vegetable crops. Interstate Publ., Danville, Ill.

Wszelaki, A. and M.D. Kleinhenz. 2003. Yield and relationships among head traits in cabbage (Brassica oleracea, L. Capitata Group) as influenced by planting date and cultivar II. Processing. HortScience 38:1355-1359. 